\title{
CLINICAL PATTERN OF POISONING AMONG PATIENTS DECLARED AS TAKING NOVEL RECREATIONAL DRUGS
} ANNA KRAKOWIAK ${ }^{1}$, MAREK BĄK ${ }^{1}$, PIOTR POLITAŃSKI², and ANNA PIEKARSKA-WIJATKOWSKA ${ }^{3}$

\author{
Nofer Institute of Occupational Medicine, Łódź, Poland \\ ${ }^{1}$ Department of Toxicology, Toxicology Unit \\ ${ }^{2}$ Department of Radiology \\ ${ }^{3}$ Department of Toxicology, Poison Information Centre
}

\begin{abstract}
Objectives: Intoxication with novel psychoactive drugs poses a significant challenge for medicine due to diagnostic difficulties, complex clinical patterns resulting from the polyethiology of poisoning, and the risk of fatal complications. Material and Methods: The authors of the present work have made a retrospective review of medical records of the patients hospitalized at the Toxicology Unit (TU), diagnosed with poisoning by novel recreational drugs. Results: In 2008-2013, 576 patients diagnosed with that type of poisoning were admitted to the TU. Of those, 192 (33.3\%) patients were positive for ethanol in addition to the most popular toxins found in the material collected from the patients, such as tetrahydrocannabinol (50 [8.6\%] patients) and amphetamine (35 [6.1\%] patients). The most frequent clinical symptoms observed on admission were: anxiety (433 [75.1\%] patients), agitation (275 [47.7\%] patients), and complaints associated with the circulatory system (225 [39.1\%] patients). In the subgroup of 104 (18.0\%) psychiatrist-interviewed people, a relationship was found between the suicidal ideation reported during history-taking and the following factors: earlier psychiatric treatment $(\mathrm{p}=0.000)$, financial problems $(\mathrm{p}=0.015)$ and prolonged unemployment $(\mathrm{p}=0.022)$. Conclusions: The observed clinical pattern may be associated with sympathomimetic syndrome due to poisoning by novel psychoactive substances. Preliminary results of this research show that financial problems and a history of psychiatric treatment may enhance suicidal ideation in patients after acute poisoning by psychoactive substances. Int J Occup Med Environ Health. 2020;33(4):445-55
\end{abstract}

Key words:

acute poisoning, clinical symptoms, novel psychoactive substances, designer drugs, suicide attempt, xenobiotic

\section{INTRODUCTION}

Designer drugs or novel recreational drugs are synonyms for the term "new psychoactive substances." They include new intoxicants or psychotropic substances which have not been specified in the relevant United Nations (UN) conventions [1,2], but which may cause a risk to public health comparable to the risk caused by the substances specified in those conventions. The action launched by the Euro- pean Union (EU) to prevent the use of novel psychoactive substances (NPSs) is a part of the policy on the Drugs Strategy 2013-2020. The aim of that action is to reduce the demand for, and supply of, designer drugs as well as illicit drugs, and to limit the risk of harmful effects on health and the society, by supporting drug strategies and launching concerted actions in the EU member states [3]. A major problem faced by toxicologists is the discrepancy

Funding: this work was supported by the Nofer Institute of Occupational Medicine (grant No. IMP 13.3 entitled "Identification and evaluation of toxic factors, kind and conditioning of acute poisonings on the basis of databases runing in the Poison Information Centre," grant manager: Anna Piekarska-Wijatkowska, Ph.D.).

Received: December 3, 2019. Accepted: March 3, 2020.

Corresponding author: Anna Piekarska-Wijatkowska, Nofer Institute of Occupational Medicine, Department of Toxicology, Poison Information Centre, św. Teresy 8 , 91-348 Łódź, Poland (e-mail: anna.piekarska@imp.lodz.pl). 
between the true composition of drugs and that declared by the manufacturer [4].

The 449 samples of psychoactive substances confiscated in 2008-2011 by law enforcement authorities that had been tested by the Institute of Judicial Expertise in Kraków were found to contain compounds belonging to various chemical classes, primarily derivatives of piperazine and cathinones, mainly 3,4-methylenedioxypyrovalerone (MDPV), 4-methylethcathinone and mephedrone [5]. In 2012, the most frequently identified compounds included synthetic cannabinoids, derivatives of phenylethylamines and cathinones (UR144, pentedrone, ethcathinone, brephedrone, 3,4-DMMC, AM-2201, JWH-081, isopentedrone, 3',4'-methylenedioxy$\alpha$-pyrrolidinobutyrophenone and MDPV) [3]. Then, in 2013, the most frequent replacement drugs were UR-144, pentedrone, isopentedrone, 3,4-DMMC, brephedrone, and ethcathinone [3].

In 2013, through an early warning system of the EU, member states reported 81 novel psychoactive substances, including 13 new phenylethylamines, 7 synthetic cathinones, 29 synthetic cannabinoids, tryptamine, piperazine, and 30 compounds that did not belong to any of the easily recognizable chemical groups [6].

A report by the European Monitoring Centre for Drugs and Drug Addition, published in 2014, shows an increase in the number of registered synthetic cannabinoids, phenylethylamines and other substances that do not fall into any of the monitored chemical groups [6].

Poisoning by NPSs is an important issue in clinical toxicology and other fields of medicine. These compounds produce characteristic symptoms common to the whole group of substances, but the symptoms may vary in their degree of severity, depending on the type of the compound and the absorbed dose. Clinical signs reported in literature include: agitation, an increased heart rate, nausea, vomiting, insomnia, urinary retention, hallucinations and psychedelic symptoms [7-10]. The potential addictive activity of piperazine derivatives has also been highlighted [10].
When the interview is ambiguous, an objective examination possibly supported by toxicological tests is an essential element of the diagnostic process. Unfortunately, few medical centers are able to perform these types of tests and, therefore, the dissemination of knowledge on the clinical symptoms that may occur as a result of the intake of those substances is extremely valuable. Some authors point out that in the group of young people attempting suicide the proportion of adolescents using psychoactive substances is significantly higher than in accidentally poisoned patients [11]. In the reported study, marihuana and amphetamine were the most commonly taken substances among patients with a history of suicide attempt [11]. The main objective of this work is to describe the clinical pattern of poisoning by NPSs. The authors of the present work have attempted to determine the relationship between the suicidal ideation declared during history-taking and selected social factors.

\section{MATERIAL AND METHODS}

A retrospective analysis has been performed of medical records of the patients hospitalized in the Toxicology Unit (TU) in Łódź, Poland, in January 2008 - December 2013. Confirmation of the intake of an NPS was obtained directly from the patient or witnesses. The study comprised patients who were diagnosed with a condition resulting from the misuse of psychoactive substances (novel recreational drugs, new psychoactive substances, novel psychoactive substances, designer drugs) - acute poisoning by another, unspecified psychoactive substance, diagnosis code T40.6 in the International Statistical Classification of Diseases and Related Health Problems 10th Revision (ICD-10) [12]. Examination results recorded in medical documentation were put into the database and were subject to a statistical analysis. Cardiovascular symptoms (palpitations, shortness of breath), heart rate, blood pressure, pupillary response (width, reaction to light), neurological disorders (dizziness, vertigo), and mental disorders (anxi- 
ety, psychomotor slowdown or agitation, hallucinations, aggressive behavior) were analyzed.

According to the adopted procedure, patients admitted to the TU should fill in the consent for hospitalization including medical examination and laboratory tests. The form was enclosed to the medical record. The study was approved by the local Bioethics Committee (Protocol No. 9/2012).

Patient's general condition was quantified according to the standardized Poisoning Severity Score (PSS) [13], which serves as the international classification to determine the severity of poisoning. It can be used for any acute poisoning regardless of the amount and type of factors that cause it.

The severity of symptoms according to PPS is determined as follows:

- 0 - no symptoms or signs characteristic of poisoning;

- 1 (minor) - mild, self-limiting and resolve spontaneously;

- 2 (moderate) - moderate, clearly evident or prolonged signs;

- 3 (severe) - severe or life-threatening symptoms;

- 4 (fatal) - death.

The result of the assessment was saved in patient's medical record (the PSS form).

The patients selected for psychiatric consultation included those with psychotic abnormalities in NPS poisoning or those who had declared the willingness to receive such consultation.

Each patient was routinely subjected to the quantitative determination of ethanol concentration in blood by gas chromatography (using SRI 310C apparatus, SRI, Torrance, USA) and to the toxicological analysis of urine. The urinary test package comprised testing for the most popular drugs (tetrahydrocannabinol [THC], amphetamines, opiates, cocaine) by enzyme immunoassay using a VIVA analyzer from Siemens, Erlangen, Germany. In addition, in the patients showing symptoms of psychomotor agitation, scopolamine, atropine and ephedrine in urine were determined qualitatively by thin layer chromatography.
The resultant information was used to develop a database containing all the above information, and then it was subjected to a statistical analysis.

\section{Statistical analysis}

The arithmetic mean $(\bar{x})$ and standard deviation (SD) were calculated for the results of the study groups at various time points. Chi-square test was used to determine differences between the analyzed variables in the group of women and men. The correlations between the studied variables were calculated using Spearman's rank correlation. The level of statistical significance $(\alpha)$ was set at 0.05 .

\section{RESULTS}

In the reporting period, 576 patients were hospitalized for poisoning by NPSs, including $4(0.69 \%)$ patients in 2008, $1(0.17 \%)$ in 2009, $219(38.02 \%)$ in 2010, $104(18.05 \%)$ in 2011, 95 (16.49\%) in 2012, and 153 (26.56\%) in 2013. In the total group of the hospitalized patients, 99 (17.2\%) were women and $477(82.8 \%)$ were men. The average age of the hospitalized patients was $23.69 \pm 6.57$ years. The average length of stay at the hospital was 2.1 days (min. 1 day, $\max 14$ days). Referring to the location from which patients arrived to the TU, the majority (391 [67.9\%] patients) were brought from home, other patients arrived from a public place - $164(28.5 \%)$ or school - $15(2.6 \%)$. It is worth noting that as many as 287 (49.8\%) of the patients reported that they had taken an NPS more than twice during their lifetime, $38(6.5 \%)$ declared taking an NPS for the first time during their lifetime, while no information on that issue could be obtained from $248(43.1 \%)$ patients. In the analyzed group of 576 patients, $27.4 \%$ (158 patients) were school or college students. As many as $53(9.2 \%)$ patients had been already treated at the TU on an earlier date. The analysis of the incidence of adverse symptoms during poisoning by NPSs is presented in Table 1. According to PSS, as many as $268(46.5 \%)$ patients were in minor, $287(49.8 \%)$ patients in moderate, while $19(3.2 \%)$ patients 
Table 1. The frequency of clinical symptoms in the group of patients hospitalized due to novel recreational drug poisoning at the Toxicology Unit in the Nofer Institute of Occupational Medicine, Łódź, Poland, in 2008-2013

\begin{tabular}{lc}
\hline \multicolumn{1}{c}{ Clinical symptom } & $\begin{array}{c}\text { Participants } \\
(\mathrm{N}=576)\end{array}$ \\
{$[\mathrm{n}(\%)]$}
\end{tabular}

in severe general condition, and the proportion of unconscious people in the study group was only 2.8\% (16 patients). The highest and the lowest values of the heart rate, systolic and diastolic blood pressure in the analyzed group of patients are presented in Table 2 .

An objective medical examination showed medium-wide pupils in 368 (63.9\%) patients. The most commonly reported clinical symptoms were: unrest reported by 433 (75.2\%) pa- tients, agitation reported by 275 (47.7\%) patients, and cardiovascular abnormalities (palpitations, shortness of breath) reported by 225 (39.1\%) patients. In addition, cardiologic disturbances, such as tachycardia and bradycardia, were detected in 305 (52.4\%) patients, while arrhythmia (supraventricular contractions) in 22 subjects (3.9\%) in the performed ECG. In the group of 576 hospitalized patients, 104 (18.1\%) subjects were aggressive. Hyperthermia, i.e., a body temperature $\geq 38^{\circ} \mathrm{C}$ was observed in 28 (4.8\%) patients, while rhabdomyolysis confirmed in the biochemical test by elevated phosphokinase (CPK) was detected in $16(2.7 \%)$ patients.

Ethanol was the most frequently detected xenobiotic in biological material, as it was found in $192(33.3 \%)$ patients. Other detected substances (in the descending order of frequency) included THC (detected in 50 [8.6\%] patients), amphetamines (35 [6.1\%] patients), ephedrine (15 [2.6\%] patients), atropine and opiates $(1.7 \%$ - each of these substances was confirmed in 10 patients) (Table 3).

Routes of NPS intake by the patients hospitalized in 20082013 were analyzed, and the results were as follows: oral intake in 368 (63.8\%) patients, inhalation in 185 (32.1\%) patients, and intravenous intake in $22(3.8 \%)$ patients.

In the group of 576 patients, psychiatric consultation was carried out in 104 (18.0\%) subjects. Among the psychiatric-consulted patients, $86(82.7 \%)$ were men and $18(17.3 \%)$ were women. The mean age of those patients was 23.8 years.

In the analyzed group of 104 patients, 36 (34.6\%) people had received psychiatric treatment in the past, 33 (31.7\%) participated in a therapy for former addicts (drug addiction therapy, drug rehabilitation), 16 (15.4\%) confirmed suicide attempt in the past, 98 (94.2\%) reported taking psychoactive substances for the purpose of stupefying, and 15 (14.4\%) declared suicidal ideation. Moreover, among these 104 patients, ethanol was confirmed to be present in the blood of 37 (35.6\%) people. The history of alcohol abuse was confirmed by $33(31.7 \%)$ people, while the history of illicit drug use was declared by as many as $86(82.7 \%)$ patients. The characteristics of the study group are shown in Table 4. 
Table 2. Descriptive analysis of age, heart rate and blood pressure in the group of patients hospitalized due to novel recreational drug poisoning at the Toxicology Unit in the Nofer Institute of Occupational Medicine, Łódź, Poland, in 2008-2013

\begin{tabular}{|c|c|c|c|c|c|c|}
\hline Variable & $\begin{array}{c}\text { Patients } \\
(\mathrm{N}=576, \\
\text { M: } 477[82.8 \%], \\
\text { W: } 99[17.2 \%]) \\
{[\mathrm{n}(\%)]}\end{array}$ & $\mathrm{M}$ & $\mathrm{Me}$ & Min. & Max & SD \\
\hline \multicolumn{7}{|l|}{ Age [years] } \\
\hline total & & 23.7 & 22.0 & 14.0 & 57.0 & 6.6 \\
\hline men & & 23.7 & 22.0 & 14.0 & 57.0 & 6.5 \\
\hline women & & 23.5 & 22.0 & 15.0 & 52.0 & 6.8 \\
\hline \multicolumn{7}{|l|}{ Heart rate $[/ \mathrm{min}]$} \\
\hline total & & 105 & 104.0 & 45.0 & 160.0 & 21.9 \\
\hline men & & 104.1 & 102.0 & 50.0 & 160.0 & 21.4 \\
\hline women & & 109.5 & 110.0 & 45.0 & 160.0 & 23.7 \\
\hline \multicolumn{7}{|l|}{ Normal heart rate } \\
\hline total & $274(47.6)$ & 87.2 & 90.0 & 60.0 & 100.0 & 10.7 \\
\hline men & $233(40.4)$ & 87.4 & 90.0 & 60.0 & 100.0 & 10.8 \\
\hline women & $41(7.1)$ & 87.7 & 88.0 & 64.0 & 100.0 & 9.9 \\
\hline \multicolumn{7}{|l|}{ Tachycardia } \\
\hline total & $297(51.6)$ & 122.2 & 120.0 & 100.0 & 160.0 & 13.8 \\
\hline men & $240(41.7)$ & 121.2 & 120.0 & 100.0 & 160.0 & 13.5 \\
\hline women & $57(9.9)$ & 126.3 & 120.0 & 104.0 & 160.0 & 14.5 \\
\hline \multicolumn{7}{|l|}{ Bradycardia } \\
\hline total & $5(0.8)$ & 52.6 & 55.0 & 45.0 & 58.0 & 5.1 \\
\hline men & $4(0.7)$ & 54.5 & 55.0 & 50.0 & 58.0 & 3.3 \\
\hline women & $1(0.2)$ & 45 & 45.0 & 45.0 & 45.0 & - \\
\hline \multirow{2}{*}{\multicolumn{7}{|c|}{$\begin{array}{l}\text { Blood pressure }[\mathrm{mm} \mathrm{Hg}] \\
\text { hypotonic }\end{array}$}} \\
\hline & & & & & & \\
\hline total & $18(3.1)$ & $90 ; 52$ & $90 ; 50$ & $75 ; 30$ & $95 ; 70$ & $5 ; 10$ \\
\hline men & $14(2.4)$ & $91 ; 52$ & $90 ; 50$ & $80 ; 40$ & $95 ; 65$ & $4 ; 8$ \\
\hline women & $4(0.7)$ & $86 ; 50$ & $90 ; 50$ & $75 ; 30$ & $90 ; 70$ & $8 ; 16$ \\
\hline \multicolumn{7}{|l|}{ normotonic } \\
\hline total & $277(48.1)$ & $121 ; 72$ & $120 ; 70$ & $100 ; 45$ & $137 ; 87$ & $10 ; 9$ \\
\hline men & $239(41.5)$ & $121 ; 71$ & $120 ; 70$ & $100 ; 50$ & $137 ; 87$ & $10 ; 9$ \\
\hline women & $38(6.7)$ & $122 ; 75$ & $125 ; 79$ & $100 ; 45$ & $135 ; 85$ & $10 ; 9$ \\
\hline \multicolumn{7}{|l|}{ hypertonic } \\
\hline total & $281(48.8)$ & $147 ; 90$ & $145 ; 90$ & $100 ; 50$ & $200 ; 140$ & $15 ; 12$ \\
\hline men & $224(38.9)$ & $149 ; 90$ & $150 ; 90$ & $100 ; 50$ & $200 ; 140$ & $15 ; 12$ \\
\hline women & $57(9.9)$ & $141 ; 92$ & $140 ; 90$ & $110 ; 70$ & $175 ; 115$ & $13 ; 9$ \\
\hline
\end{tabular}

Hypotension - systolic tension $<100 \mathrm{~mm} \mathrm{Hg}$ and diastolic tension $<60 \mathrm{~mm} \mathrm{Hg}$; hypertension - systolic tension $\geq 140 \mathrm{~mm} \mathrm{Hg}$ or diastolic tension $\geq 90 \mathrm{~mm} \mathrm{Hg}$; normal blood pressure: $100 \mathrm{~mm} \mathrm{Hg} \leq$ systolic tension < $140 \mathrm{~mm} \mathrm{Hg}$ and diastolic tension < $90 \mathrm{~mm} \mathrm{Hg}$; tachycardia: heart rate >100/min; bradycardia $<60 / \mathrm{min}$. 
Table 3. Substances found in the biological material in the group of patients hospitalized due to novel recreational drug poisoning $(\mathrm{N}=576)$ at the Toxicology Unit in the Nofer Institute of Occupational Medicine, Łódź, Poland, in 2008-2013

\begin{tabular}{lc}
\hline \multicolumn{1}{c}{ Substance } & $\begin{array}{c}\text { Positive result } \\
{[\mathrm{n}(\%)]}\end{array}$ \\
\hline Ethanol & $192(33.3)$ \\
Tetrahydrocannabinol & $50(8.6)$ \\
Amphetamine & $35(6.1)$ \\
Ephedrine & $15(2.6)$ \\
Atropine & $10(1.7)$ \\
Opiates & $10(1.7)$ \\
Dextromethorphan & $4(0.7)$ \\
Scopolamine & $1(0.2)$ \\
Cocaine & $3(0.5)$ \\
Carbamazepine & $2(0.3)$ \\
\hline
\end{tabular}

The results of the statistical analysis in the group of 104 patients revealed significant differences between men and women in the frequency of the following social factors:

- economic activity - unemployment (46 [53.5\%] vs. 15 [83.3\%]),

- economic activity - education (30 [34.9\%] vs. 11 [61.1\%]),

- previous psychiatric treatment (25 [29.1\%] vs. 11 [61.1\%]),

- family problems (13 [15.1\%] vs. 11 [61.1\%]),

- problems at school (3[3.5\%] vs. 4 [22.2\%]),

- financial problems (6 [7\%] vs. 4 [22.2\%]).

Those factors were observed to affect significantly more frequently women than men $(\mathrm{p}<0.05)$.

Among the group of 104 patients, no significant differences were noted in the analyzed social factors and the risk of suicide attempt: the reason for the intake of a psychoactive substance - the intention to become intoxicated, a history of alcoholic problem, a history of illicit drug use, a history of participation in drug addiction treatment, a history of suicide attempt, or a heartbreak
Table 4. Characteristics of the group of patients after psychiatric consultation, hospitalized due to novel recreational drug poisoning at the Toxicology Unit in the Nofer Institute of Occupational Medicine, Łódź, Poland, in 2008-2013

\begin{tabular}{lc}
\hline \multicolumn{1}{c}{ Variable } & $\begin{array}{c}\text { Participants } \\
(\mathrm{N}=104)\end{array}$ \\
\hline Gender [n (\%)] & $18(17.3)$ \\
female & $86(82.7)$ \\
male & $23.8 \pm 4.78$ \\
Age [years] (M \pm SD) & \\
Professional activity [n (\%)] & $23(22.1)$ \\
permanent employment & $24(23.1)$ \\
casual employment & $41(39.4)$ \\
education & $61(58.7)$ \\
unemployment & \\
History [n (\%)] & $36(34.6)$ \\
psychiatric treatment & $16(15.4)$ \\
suicide attempt & $33(31.7)$ \\
alcohol drinking - harmful drinking & $86(82.7)$ \\
drug abuse & $33(31.7)$ \\
participation in drug addiction treatment & $37(35.6)$ \\
Taking psychoactive substances & \\
by ethanol-intoxicated patients [n $(\%)]$ & $98(94.2)$ \\
Taking psychoactive substances & \\
to become intoxicated [n $(\%)]$ & $15(14.4)$ \\
Suicidal ideation [n $(\%)]$ &
\end{tabular}

as the reason for the intake of a psychoactive substance $(\mathrm{p}>0.05)$.

In the subgroup of 104 psychiatric-consulted people, a significant correlation was found to occur between the risk of suicide attempt and financial problems (Spearman's correlation coefficient $r=0.237, p=0.015$ ), a history of psychiatric treatment (Spearman's correlation coefficient $r=0.392, p=0.000)$, professional activity - casual employment (Spearman's correlation coefficient $r=0.225$, $\mathrm{p}=0.022)$ (Table 5).

In each hospitalized patient, a preliminary assessment of the risk of death, i.e., air, breathing and circulation 
Table 5. Relationship between the analyzed parameters and the risk of suicide attempt in the group of patients hospitalized at the Toxicology Unit in the Nofer Institute of Occupational Medicine, Łódź, Poland, in 2008-2013

\begin{tabular}{lcc}
\hline \multicolumn{1}{l}{ Social parameter } & $\begin{array}{c}\text { Spearman's correlation } \\
\text { coefficient }\end{array}$ & $\mathrm{p}$ \\
\hline Problems & & 0.99 \\
$\quad$ at school & -0.001 & 0.01 \\
financial & 0.23 & \\
Employment & & 0.26 \\
permanent employment & 0.11 & 0.02 \\
casual employment & -0.22 & 0.91 \\
unemployment & 0.01 & \\
History & & 0.00 \\
psychiatric treatment & 0.39 & 0.07 \\
suicide attempt & -0.17 & 0.18 \\
participation in drug addiction treatment & 0.13 & 0.33 \\
Taking psychoactive substances by ethanol-intoxicated patients & 0.09 & 0.12 \\
Living with parents & -0.15 & \\
\hline
\end{tabular}

$(\mathrm{ABC})$ assay was performed, revealing that 8 patients required intubation due to respiratory failure. Treatment with fluids was applied in 561 (97.3\%) patients. Because of psychomotor agitation and aggressive behavior, direct coercion was applied to $71(12.3 \%)$ patients. As many as $411(71.3 \%)$ patients required the application of sedatives (benzodiazepines). In addition, $70(12.1 \%)$ patients in whom the psychotic disorder persisted in spite of the applied therapy were transferred to psychiatric wards for further treatment; 138 (23.9\%) patients were treated with $\beta$-blockers because of the diagnosed adverse effects and/ or ECG abnormalities (tachycardia was the most frequent, while arrhythmia was less common). At their own request, before the completion of the diagnostic/treatment process, 269 (46.7\%) patients were released from the TU.

\section{DISCUSSION}

The results of this study show that NPSs have been available in the Polish market since 2008. They were brought to Poland as legitimate products, initially through mail order, and then, in 2008, the first shops emerged, offering a variety of "collectionner products," allegedly not designed for human consumption. In Poland, the first attempt to fight designer drugs was the amendment to the Act on Counteracting Drug Addiction of 20 March 2009 [14], extending the list of prohibited substances. On November 2, 2010, the Chief Sanitary Inspector issued a decision to close NPS shops, warehouses and production sites [15]. The above mentioned decision caused a substantial decrease in the number of patients hospitalized after the intake of NPSs in Łódź in 2011 and 2012. Unfortunately, it was not possible to restrict the availability of NPSs in Poland, as evidenced by a growing number of patients hospitalized for poisoning by those substances since 2013.

Access to NPSs is relatively easy. The psychoactive substances produced outside Europe can be purchased mainly from online retailers, in specialist shops, and even in the illicit drug market. The internet is a place not only for the sales of designer drugs, but also for the exchange of information and discussion among young devotees of psycho- 
active substances intake. The "Psychonaut Web Mapping Project" analyzed the information appearing in the web pages and forums in 7 European countries (UK, Spain, Italy, Finland, Norway, Belgium and Germany), in which people spoke out about psychoactive substances they were using. The most popular of the 414 monitored psychoactive substances were: 121 vegetable compounds, 153 chemical compounds, and 140 mixed compounds. Within 2 years, there has been a sharp increase in the so-called "spice drugs," mephedrone, naphyrone, 5,6-methylenedioxy-2-aminoindane (MDAI) and MDPV [16].

The authors are aware that the limitations of this study include the lack of identification of novel psychoactive substances in biological material, which would allow the assignment of a given pattern of the poisoning to a specific psychoactive substance [17]. Please also note that products containing psychoactive substances usually do not contain the declared chemical, and their composition, both quantitative and qualitative, significantly differs even between products marketed under the same name [4].

In the group of 576 patients, the pattern of poisoning was usually mild in its somatic aspect, with poorly expressed symptoms of sympathomimetic syndrome. The most commonly reported clinical symptoms were: unrest reported by $433(75.2 \%)$ patients, agitation reported by 275 (47.7\%) patients, and cardiovascular abnormalities reported by $225(39.1 \%)$ patients.

Also in the study by the Center for Toxicology and Internal Medicine in Poznań, the most commonly observed clinical signs of poisoning by designer drugs included symptoms from the nervous system (ravings, hallucinations, anxiety, agitation, logorrhea, generalized weakness, vertigo, drowsiness) and the cardiovascular system (high blood pressure, tachycardia, chest pain), and mydriasis [2]. It seems reasonable to assume that those symptoms could be produced by $\beta$-ketoamines and compounds characterized by similar activity (e.g., mephedrone, butylone, methylone, buphedrone, methylenedioxypyrovalerone) [18-22].
In the study by James et al. [20], the most commonly observed adverse events associated with the intake of mephedrone were: agitation, tachycardia, unrest, ravings, chest pain, and nausea.

Clinical symptoms similar to those observed in the poisoning by cathinones were noted in the poisoning by derivatives of $\mathrm{N}$-pyrrolidine phenethylamine. Pyrovalerone is a representative of those compounds, and MDPV is probably a variety of pyrovalerone. The pattern of poisoning by that substance comprised also hallucinations and psychotic disorders [22]. Piperazine derivatives constitute another group of substances acting in a similar way on the systems of 3 biogenic amines (dopamine, norepinephrine, serotonin). The most commonly reported side effects after taking piperazine derivatives include: anxiety, psychomotor agitation, palpitations, vomiting, and confusion [23,24]. Moreover, $>10 \%$ of the patients experienced dizziness, convulsions, insomnia, headache, and involuntary movements [23,24]. Other authors point to the likelihood of acute renal failure due to poisoning by that group of substances, requiring dialysis treatment, without the accompanying rhabdomyolysis [25].

Synthetic cannabinoids included in sample materials constitute another group of designer drugs confirmed to be available in Poland [26]. These compounds are full antagonists of the $\mathrm{CB} 1$ receptor found in the central nervous system. Their intake results in clinical symptoms similar to those that accompany tetrahydrocannabinol poisoning [27]. Few authors reported likely psychical symptoms, such as anxiety and changes in perception, which may also be accompanied by palpitations [28,29].

Single cases of psychotic disorders persisting even for a few days after the intake of psychoactive substances belonging to the group of synthetic cannabinoids have been also reported [30]. Some authors have reported likely tachycardia and cardiac arrhythmia after the intake of synthetic cannabinoids $[29,30]$. The biological material collected from the patients hospitalized at the TU in 
Łódź confirmed the presence of other drugs and medications, such as amphetamine, tetrahydrocannabinol, atropine, ephedrine, carbamazepine, and benzodiazepines. The presented results may point to the phenomenon of polydrug use; however, please keep in mind that some of the discussed substances could be present in the samples of materials confiscated from shops in Poland, as suggested by the information cited above [31]. It is worth noting that empty NPS packages were found among the belongings of all patients whose biological material had been found to contain stimulants. It is, therefore, reasonable to suppose that the clinical pattern of the poisoning was likely to be affected also by those chemicals.

The authors of the present work are not aware of any reports of studies attempting an assessment of the relationship between a positive history of suicidal ideation in NPSpoisoned patients and various social factors.

A correlation was detected in the subgroup of 104 psychiatrist-consulted patients between the risk of suicide attempt and financial problems [32]. Some studies have shown a relationship between a low material status, a poor financial situation and suicidal behavior; however, according to the authors of this study, this hypothesis should be verified in a larger group of patients with clinical signs of intoxication by novel psychoactive substances $[33,34]$.

In this study, a correlation was also found between the risk of suicide and earlier suicide-related psychiatric treatment. Other researchers have found that suicidal ideation occurs significantly more often in patients with clinical mental health disorders than in healthy subjects [35].

\section{CONCLUSIONS}

Symptomatology in the patients treated at the TU in Łódź may correspond to the effects of NPSs. Poisoning by those substances is an important issue because of diagnostic difficulties, the likely elevated frequency and possible complications resulting from abuse. The limitations of this work include the inability to identify NPSs in biological material and the likely significant heterogeneity of the substances used by the patients. The preliminary results of the study indicate that difficult financial circumstances and earlier psychiatric treatment may be factors that predispose patients to suicidal ideation after past acute poisoning by NPSs.

\section{REFERENCES}

1. United Nations Office on Drugs and Crime. The United Nations Single Convention on Narcotic Drugs [Internet]. Geneva: United Nations; 1961 [cited 2013 Jan 4]. Available from: http://www.unodc.org/pdf/convention_1961_en.pdf.

2. United Nations Office on Drugs and Crime. The United Nations Convention on Psychotropic Substances [Internet]. Geneva: United Nations; 1971 [cited 2013 Jan 4]. Available from: http://www.unodc.org/pdf/convention_1971_en.pdf.

3. Chief Sanitary Inspectorate. [Report on replacement drugs three years of the combat against designer drugs in Poland] [Internet]. Warsaw: The Inspectorate; 2013 [cited 2014 Oct 10]. Available from: www.gis.gov.pl/ckfinder/userfiles/files/Środki\% 20Zastępcze/raport2013. Polish.

4. Chief Sanitary Inspectorate. [New Designer Drugs in Poland 2017-2018]. Warsaw: The Inspectorate; 2019. Polish.

5. Zuba D, Byrska B. Prevalence and co-existence of active components of „legal high”. Drug Test Analys. 2012;5(6):420-9, https://doi.org/10.1002/dta.1365.

6. European Monitoring Centre for Drugs and Drug Addiction. European Drug Report 2014 Trends and developments [Internet]. Luxembourg: Publications Office of the European Union, 2014 [cited 2014 Sep 5]. Available from: http://www.emcd da.europa.eu/event/2014/05/launch-2014-european-drug-re port_en.

7. Hill SL, Thomas SHL. Clinical toxicology of newer recreational drugs. Clin Toxicol (Phila). 2011;49:705-9, https://doi. org/10.3109/15563650.2011.615318.

8. Butler RA, Sheridan JL. Highs and lows: patterns of use, positive and negative effects of benzyl-piperazine-containing party pills (BZP-party pills) among young people in New Zealand. Harm Reduct J. 2007;19(18):1-10. 
9. Sawicka J, Czyżewska S, Winnicka R, Politański P, ŚwiderskaKiełbik S, Kołaciński Z, et al. Acute novel drugs poisoning among patients of Nofer Institute of Occupational Medicine in Lodz, Toxicology Unit, hospitalized in the years 2008-2012 - epidemiology, clinical state. Przegl Lek. 2013;70(8):520-4.

10. Pourmand A, Mazer-Amirshahi M, Chistov S, Li A, Park M. Designer drugs: Review and implications for emergency management. Hum Exp Toxicol. 2018;37(1):94-101, https:// doi.org/10.1177/0960327117698542.

11. Foryś Z. Suicidal poisoning in relation to use of psychoactive substances in adolescents. Przegl Lek. 2007;64(4-5):222-6.

12. ICD-10. International Statistical Classification of Diseases and Related Health Problems. X Revision. Kraków: Vesalius; 1994.

13. Persson H, Sjöberg G, Haines J, Pronczuk de Garbino J. Poisoning Severity Score: Gradng of acute poisoning. J Toxicology Clin Toxicol. 1998;36:205-13, https://doi.org/10.3109/ 15563659809028940.

14. [Act of 20 March, 2009, amending the Act on preventing drug addiction. J Laws 2009, item 63,520]. Polish.

15. Chief Sanitary Inspectorate. [Decision of 2 October, 2010. Reference GIS-BI-073-239/RS/10]. Polish.

16. Deluca P, Davey Z, Corazza O, Di Furia L, Farre M, Holmefjord Flesland L, et al. Identifying emerging trends in recreational drug use; outcomes from the Psychonaut Web Mapping Project. Prog Neuropsychopharmacol Biol Psychiatry. 2012;39:221-6, https://doi.org/10.1016/j.pnpbp.2012.07.011.

17. Zawilska J, Słomiak K, Wasiak M, Woźniak P, Massalski M, Krupa E, et al. $\beta$-cathinone derivatives - a new generation of dangerous psychostimulant „designer drugs”. Przegl Lek. 2013;70(6):386-91.

18. Wood D, Davies S, Green S, Button J, Holt D, Ramsey J. Case series of individual with analytically confirmed acute mephedrone toxicity. Clin Toxicol (Phila). 2010;48:924, https:// doi.org/10.3109/15563650.2010.531021.

19. Wood DM, Davies S, Puchnarewicz M, Button J, Archer R, Ovaska H, et al. Recreational use of mephedrone (4-methylmethcathinone, 4-MMC) with associated sympathomi- metic toxicity. J Med Toxicol. 2010;6:327-30, https://doi. org/10.1007/s13181-010-0018-5.

20. James D, Adams RD, Spears R, Cooper G, Lupton DJ, Thomson JP, et al. Clinical characteristics of mephedrone toxicity reported to the UK. National Poisons Information Service. Emerg Med J. 2011;28(8):686-9, https://doi. org/10.1136/emj.2010.096636.

21. Spiller HA, Ryan ML, Weston RG, Jansen J. Clinical experience with and analytical confirmation of bath salts and legal highs (synthetic cathinones) in the United States. Clin Toxicol (Phila). 2011;49:499-505, https://doi.org/10.3109/155636 50.2011.590812.

22. Meltzer PC, Butler D, Deschamps J, Madras BK. 1-(4-Methylphenyl-2-pymolidin-1-yl-pentan-1-one (Pyrovalerone) analogues a promising class of monoamine uptake inhibitors. J Med Chem. 2006;49:1420-32, https://doi.org/10.1021/jm 050797a.

23. Gee P, Gilbert M, Richardson S, Moore G, Paterson S, Graham P. Toxicity from the recrational use of 1-benzylpiperazine. Clin Toxicol (Phila). 2008;46:802, http://doi. org/10.1080/15563650802307602.

24. Gee P, Jerram T, Bowie D. Multiorgan failure from 1-benzylpiperazine ingestion - legal high or lethal high? Clin Toxicol (Phila). 2010;48:230, http://doi.org/10.3109/155636 51003592948 .

25. Alansari M, Hamilton D. Nephrotoxicity of BZP-based herbal part pills: a New Zealand case report. N Z Med J. 2006;119:1959.

26. Fijałek Z. Designer drugs - the problem of new generation synthetic drugs - preliminary analysis results. In: DESIGNER DRUGS - New Challenges for the Effective Operation of Public Institutions Conference Materials, 2010 Dec 8; Warsaw, Poland.

27. Thornton SL, Lo J, Clark RF, Wu AHB, Gerona RR. Simultaneous detection of multiple designer drugs in serum, urine and CSF in a patient with prolonged psychosis. Clin Toxicol (Phila). 2012;50:1165-8, https://doi.org/10.3109/15563650.20 12.744996 . 
28. Every-Palmer S, Warning. Legal synthetic cannabinoid - receptor agonists such as JWH-018 may precipitate psychosis in vulnerable individuals. Addiction. 2010;105:1859-61, https://doi.org/10.1111/j.1360-0443.2010.03119.x.

29. Hurst D, Loeffler G, McLay R. Psychosis associated with synthetic cannabinoids agonists: a case series. Am J Psychiatry. 2011;168:1119, https://doi.org/10.1176/appi.ajp.2011.11010176.

30. Lapoint J, James LP, Moran CL, Nelson LS, Hoffman RS, Moran JH. Severe toxicity following synthetic cannabinoid ingestion. Clin Toxicol (Phila). 2011;49:760-4, https://doi.org/ 10.3109/15563650.2011.609822.

31. Byrska B, Zuba D, Pyta P. Analysis of designer drug composition. In: XXVIII Konferencja Toksykologów Sądowych "Nowe narkotyki" - współczesne wyzwanie dla toksykologów sądowych; 2011 May 18-20; Wrocław - Szklarska Poręba, Poland. Polish.
32. Breet E, Goldstone D, Bantjes J. Substance use and suicidal ideation and behaviour in low- and middle-income countries: a systematic review. BMC Public Health. 2018;18:549, https://doi.org/10.1186/s12889-018-5425-6.

33. Merecz D, Rosa K, Sobala W. Suicidal ideation and suicidal attempts. Modeling of the relationship between the risk factors. Suicydologia. 2006;2(1):76-87.

34. Neeleman J, de Graaf R, Vollebergh W. The suicidal process prospective comparison between early and later stage. J Affect Disord. 2004;82:43-52, https://doi.org/10.1016/j.jad. 2003.09.005.

35. Vilo KM, Timonen MJ, Hakko HH, Särkioja T, MeyerRochow VB, Räsänen K. Lifetime prevalence of physical diseases and mental disorders in young suicide victims. Psychosom Med. 2005;67:241-5, https//doi.org/10.1097/01.psy. 0000151488.71789.7f.

This work is available in Open Access model and licensed under a Creative Commons Attribution-NonCommercial 3.0 Poland License - http://creativecommons.org/ licenses/by-nc/3.0/pl/deed.en. 